\title{
QUALIDADE FÍSICA DE UM CAMBISSOLO SOB SISTEMAS DE MANEJO ${ }^{(1)}$
}

\author{
Jaedson Cláudio Anunciato Mota ${ }^{(2)}$, Alcione Guimarães Freire ${ }^{(3)}$ \& Raimundo Nonato de \\ Assis Júnior ${ }^{(2)}$
}

\section{RESUMO}

A Chapada do Apodi vem se destacando como um promissor polo de fruticultura irrigada em virtude da potencialidade agrícola dos seus solos, que são submetidos a diferentes tipos de manejo, condicionando mudanças em seus atributos físicos. Este trabalho teve como objetivo avaliar fisicamente um Cambissolo cultivado com mamoeiro (Carica papaya L.), sob dois sistemas de manejo, comparado com um sob vegetação nativa secundária. Foram coletadas amostras de solo com estruturas deformada e indeformada para determinação de: granulometria, argila dispersa em água, densidade do solo e de partículas, estabilidade de agregados, carbono orgânico e resistência à penetração. Foram calculados o grau de floculação das argilas e o teor de matéria orgânica. No campo, foi realizado ensaio de condutividade hidráulica do solo. Os dados experimentais foram analisados considerando o delineamento inteiramente casualizado, adotandose para todas as análises o esquema em parcela subdividida $3 \times 3 \times 5$ (dois sistemas de manejo do solo - plantio do mamoeiro em sulco e camalhão - e mata nativa secundária; três camadas de solo - 0,0-0,1; 0,1-0,2; e 0,2-0,3 m; e cinco repetições), exceção para a condutividade hidráulica, em que se adotou o esquema fatorial $3 \mathbf{x}$ 2 x 5 (dois sistemas de manejo do solo e mata nativa secundária; duas tensões - 0 e $5 \mathrm{hPa}$; e cinco repetições). Foram aplicados os testes de Kolmogorov-Smirnov para verificar a normalidade dos dados, o F para a análise de variância e o de Tukey para a comparação de médias, todos a $5 \%$. Concluiu-se que a hipótese de que os sistemas de cultivo pioram os solos fisicamente foi refutada, indicando que a qualidade dos atributos do solo sob cultivo, em geral, está mantida ou melhorada em relação à condição atual da mata nativa secundária; o decréscimo do teor de matéria orgânica, da porcentagem de agregados estáveis na classe de 4,76-2,00 mm de diâmetro e do diâmetro médio ponderado em solo cultivado, apesar de ainda

\footnotetext{
(1) Parte da Dissertação de Mestrado do segundo autor; financiamento do CNPq (Conselho Nacional de Desenvolvimento Científico e Tecnológico) e FUNCAP (Fundação Cearense de Apoio ao Desenvolvimento Científico e Tecnológico). Recebido para publicação em 3 de julho de 2012 e aprovado em 4 de julho de 2013.

(2) Professor do Departamento de Ciências do Solo, Universidade Federal do Ceará - UFC. Av. da Universidade, 2853, Benfica. CEP 60020-181 Fortaleza (CE). E-mail: jaedson.mota@ufc.br; assisjr@ufc.br

(3) Doutorando do Programa de Pós-Graduação em Agronomia - Solos e Nutrição de Plantas, UFC. E-mail: alcionegf@hotmail.com
} 
estarem distantes de limites considerados críticos, é indicador da necessidade de adoção de práticas de manejo que evitem o desencadeamento de um processo de degradação do solo; e os indicadores de qualidade foram sensíveis às alterações provocadas pelos sistemas de manejo do solo e, portanto, podem ser utilizados como fonte para a interpretação da dinâmica de processos físicos do solo no tempo.

Termos de indexação: Chapada do Apodi, qualidade do solo, fruticultura irrigada.

\title{
SUMMARY: PHYSICAL QUALITY OF AN INCEPTISOL (CAMBISOL) UNDER MANAGEMENT SYSTEMS
}

\begin{abstract}
The Apodi Tableland is becoming known as a promising center of irrigated fruit production because of the agricultural potential of its soils. The physical properties of these soils are modified by different management types. The purpose of this study was to evaluate the physical properties of an Inceptisol under papaya (Carica papaya L.) in two tillage systems, compared to the same soil type under secondary forest. Samples of disturbed and undisturbed soil were collected for analysis of texture, clay dispersed in water, bulk density, particle density, aggregate stability, organic carbon, and penetration resistance. The clay flocculation degree and organic matter content were calculated. The soil hydraulic conductivity was tested in the field. The $3 x$ $3 \times 5$ factorial scheme consisted of two soil management systems (papaya planted in furrow and ridge) and native secondary forest; three soil layers (0-0.1;0.1-0.2, and 0.2-0.3 m), in five replications, except for the hydraulic conductivity, for which a factorial $3 \times 2 \times 5$ (two soil management systems and secondary forest; two tensions - 0 and $5 \mathrm{hPa}$; five replications) was used, in a completely randomized design. The Kolmorogov-Smirnov Test was used to verify the normality of data distribution, the F Test for analysis of variance and Tukey's test for mean comparison, all at $p=0.05$. It was concluded that: a) the hypothesis that the tillage systems worsen the physical soil quality was refuted, indicating that the quality of the cultivated soil was generally maintained or improved in relation to the status of the native soil; b) the decrease of the organic matter content, percentage of stable aggregates (diameter class $4.76-2.00 \mathrm{~mm}$ ) and the mean weighted diameter in cultivated soil, although still far from critical limits, indicate the need for management practices that avoid soil degradation; c) the soil quality indices were sensitive to changes caused by soil management systems and can therefore be used as a basis of interpretation of the dynamics of soil physical processes in time.
\end{abstract}

Index terms: Apodi Tableland, soil quality, irrigated fruit production.

\section{INTRODUÇÃO}

A Chapada do Apodi, localizada na porção leste do Estado do Ceará, na divisa com o Estado do Rio Grande do Norte, vem se destacando como promissor polo de fruticultura irrigada, em virtude da potencialidade agrícola dos seus solos, topografia plana e viabilidade de irrigação. Nessa região, pesquisas relacionadas à qualidade do solo, especificamente quanto à qualidade física, são escassas e, portanto, tornam-se necessárias em um curto decurso de tempo.

Nos últimos anos, pesquisadores da área de ciência do solo têm se preocupado com o tema qualidade do solo, procurando identificar e selecionar indicadores associados a determinadas funções que esse deve desempenhar e definir valores quantitativos e mensuráveis desses indicadores. As propriedades físicas do solo influenciam o ambiente e a escolha do melhor manejo a ser adotado, sendo decisivas no sucesso ou fracasso de uma exploração agrícola.

Estudos relativos ao monitoramento da qualidade do solo pelos atributos físicos são importantes para a avaliação e manutenção da sustentabilidade dos sistemas agrícolas, além de sinalizar o manejo adequado do ambiente, visando à sua conservação e produtividade. Um atributo indicador da qualidade do solo deve, portanto, ser sensível às variações do manejo ao qual o solo está submetido. Atributos como densidade do solo, teor de matéria orgânica, estabilidade de agregados, resistência à penetração $\mathrm{e}$ condutividade hidráulica podem ser alterados pelo uso e manejo do solo, sendo bastante utilizados como indicadores da qualidade física do solo.

De acordo com Klein (2008), os valores de densidade dos solos (Ds) agrícolas variam de 0,9 a $1,8 \mathrm{~g} \mathrm{~cm}^{-3}$, dependendo da textura e do teor de matéria orgânica do solo. De maneira geral, quanto mais elevada for a Ds pior será sua estruturação e menor a sua porosidade total e, consequentemente, maiores serão as restrições para o crescimento e desenvolvimento das plantas (Kiehl, 1979). Em estudo avaliando sistemas de preparo do solo, Assis \& Lanças (2005) obtiveram menores valores de densidade na camada superficial sob mata nativa e sistema de plantio direto, em relação ao preparo convencional, sendo justificado 
pelo maior teor de matéria orgânica que favorece melhor estruturação e, por conseguinte, redução na Ds.

O teor de matéria orgânica não é propriamente um indicador de qualidade física do solo, mas influencia direta e indiretamente várias propriedades que estabelecem a sua qualidade física (Christensen \& Johnston, 1997). Um dos processos do solo mais influenciados pela matéria orgânica é a agregação. A partir do seu efeito sobre a agregação do solo, indiretamente são interferidos os seus atributos físicos, como densidade, porosidade, aeração, capacidade de retenção e infiltração de água, entre outros, que são fundamentais à capacidade produtiva do solo (Bayer \& Mielniczuk, 2008). Segundo Mota (2004), em estudos na Chapada do Apodi, RN, a baixa densidade de vegetação, aliada às elevadas temperaturas, tem se constituído fator limitante ao aporte de compostos orgânicos ao sistema, sendo imprescindível a adoção de sistemas de manejo que condicionem maior aporte de material orgânico ao solo.

O tamanho do agregado determina sua suscetibilidade à movimentação pelo vento e pela água, o espaço poroso e o seu arranjo, interferindo na movimentação da água, transferência de calor, aeração e porosidade (Klein, 2008). Solos que apresentam boa agregação possuem diâmetro maior em seus agregados, o que facilita a proteção da matéria orgânica e o melhor fluxo e armazenamento de água no solo. Em estudo sobre os efeitos de sistemas de manejo na agregação do solo, Salton et al. (2008) encontraram relação entre estabilidade dos macroagregados com o teor de $\mathrm{C}$ orgânico no solo.

A resistência do solo à penetração é uma propriedade física que limita o crescimento das raízes, acarretando em redução da produtividade das culturas, sendo um atributo útil na avaliação da qualidade física do solo, pois permite identificar áreas potencialmente limitantes ao crescimento das raízes e estabelecem a umidade e Ds, críticas para o desenvolvimento das plantas (Imhoff et al., 2000). Segundo Carvalho et al. (2006), valores de resistência à penetração variando entre 1,29 e 2,87 $\mathrm{MPa}$ não restringiram a produtividade da cultura do feijão; todavia, considerando o conceito de intervalo hídrico ótimo, Silva et al. (1994) propuseram o valor de 2,0 $\mathrm{MPa}$ como limite crítico para o crescimento do sistema radicular.

A condutividade hidráulica do solo é uma medida da habilidade desse em transmitir água (Wu et al., 1999), sendo dependente da geometria do espaço poroso, apresentando bastante variação de solo para solo e, também, para o mesmo solo com variações estruturais, de compactação etc. (Reichardt \& Timm, 2004). Por ser dependente de propriedades do solo, a condutividade pode ser útil na diferenciação dos efeitos de sistemas de manejo na movimentação de água no perfil desse.

Este trabalho partiu das hipóteses de que os sistemas de manejo utilizados na área em estudo, por fazer uso de máquinas e implementos que modificam o ambiente físico do solo, alteram sua qualidade, piorando-a em comparação a um solo sob vegetação natural; e as alterações do solo podem ser aferidas a partir de índices e interpretadas, sob o aspecto de sua qualidade física. Portanto, avaliando a qualidade física do solo sob cultivo de mamoeiro irrigado na Chapada do Apodi, objetivaram-se analisar os efeitos de diferentes sistemas de manejo sobre propriedades físicas do solo relacionadas à sua qualidade, indicar os riscos de degradação do ambiente impostos pelo uso agrícola atual e, se necessário, apresentar alternativas para os sistemas de manejo do solo e da cultura do mamoeiro comprometedores da sustentabilidade da atividade agrícola.

\section{MATERIAL E MÉTODOS}

A área avaliada quanto à qualidade física do solo está localizada na Chapada do Apodi, situada no Estado do Ceará, município de Limoeiro do Norte, e tem em seu centro as coordenadas $5^{\circ} 08^{\prime} 04,37^{\prime \prime} \mathrm{S}$ e $37^{\circ} 54^{\prime}$ $56,58^{\prime \prime}$ W e $5^{\circ} 08^{\prime} 32,23^{\prime \prime} \mathrm{S}$ e $37^{\circ} 54^{\prime} 07,60^{\prime \prime} \mathrm{W}$, para a área cultivada com mamoeiro e sob vegetação natural, respectivamente, a uma altitude de $145 \mathrm{~m}$. Antes do plantio com mamoeiro, a área era cultivada com milho e feijão na estação chuvosa. A área de mata era composta por vegetação secundária típica da caatinga, com sinais de degradação por cultivos pretéritos, cujo manejo era por vezes inadequado. No período de escassez de chuvas era mantida apenas com vegetação espontânea típica da Caatinga. Para a implantação do pomar de mamoeiro, o solo foi preparado com grade aradora, em duas passagens, na camada de 0,0-0,2 $\mathrm{m}$. Na sequência, foram aplicados os dois tratamentos de manejo do solo, camalhão e sulco. Fez-se o levantamento dos camalhões a uma altura de $0,25 \mathrm{~m}$, com enxada rotativa, e abertura dos sulcos com sulcador a $0,25 \mathrm{~m}$ de profundidade, ambos com 0,40 $\mathrm{m}$ de largura. Quando da coleta de solo para fins de avaliação de sua qualidade física, o mamoeiro havia sido implantado há cinco e 11 meses no sistema em camalhão e sulco, respectivamente.

Para fins de avaliação da qualidade física do solo, foram contempladas as duas formas de manejo do solo (plantio do mamoeiro em sulco e camalhão) e uma situação de mata nativa secundária, até a profundidade de $0,3 \mathrm{~m}$, nas camadas de $0,0-0,1,0,1$ 0,2 e 0,2-0,3 m. A área de mata nativa secundária dista cerca de $1.600 \mathrm{~m}$ das áreas cultivadas. Foram coletadas amostras de solo com estruturas deformada e indeformada nas camadas citadas anteriormente, considerando para o solo cultivado a parte central do sulco ou camalhão conforme o caso. As amostras com estrutura indeformada foram coletadas utilizando amostrador tipo Uhland, em anéis de aço com dimensões de $0,05 \mathrm{~m}$ de altura por $0,05 \mathrm{~m}$ de diâmetro. 
O solo, classificado como Cambissolo (Brasil, 1973), foi avaliado quanto aos seguintes aspectos: granulometria, argila dispersa em água, grau de floculação, matéria orgânica, densidade das partículas (Dp), densidade do solo (Ds), estabilidade de agregados, diâmetro médio ponderado, resistência à penetração $\mathrm{e}$ condutividade hidráulica.

A granulometria foi determinada pelo método da pipeta (Gee \& Bauder, 1986). Determinou-se a argila dispersa em água pelo mesmo método adotado para a análise granulométrica, suprimindo apenas o dispersante químico. $\mathrm{O}$ grau de floculação foi obtido com base na equação

$$
G F=\left(\frac{\text { argilatotal }- \text { argila dispersaem água }}{\text { argila total }}\right)
$$

Determinou-se o carbono orgânico, pela oxidação da matéria orgânica via úmida com dicromato de potássio, em presença de $\mathrm{H}_{2} \mathrm{SO}_{4}$ e aquecimento externo, e titulação do excesso de dicromato com sulfato ferroso amoniacal e, a partir dele, multiplicou-o pelo fator 1,724, encontrando a quantidade de matéria orgânica (Yeomans \& Bremner, 1988).

A densidade do solo (Ds) foi determinada em amostras de solo indeformado, coletadas com amostrador tipo Uhland e secas a $105^{\circ} \mathrm{C}$ até massa constante (Blake \& Hartge, 1986b) e a densidade das partículas, pelo método do balão volumétrico (Blake \& Hartge, 1986a).

Para a análise de estabilidade de agregados, adotouse o método por via úmida para medir a quantidade $\mathrm{e}$ distribuição do tamanho dos agregados que são estáveis em água, relacionando-os com os que não se desintegram pela tamisação (Kemper \& Rosenau, 1986). Com o objetivo de estimar o diâmetro médio ponderado $(D M P)$, o teor de agregados em cada peneira foi expresso em quatro classes de diâmetro de agregados: $4,76-2,00 ; 2,00-1,00 ; 1,00-0,50 ;$ e 0,50 $0,25 \mathrm{~mm}$, pela equação:

$$
\% A E C=[(M a-M p) /(M s-M w-\Sigma M p)] 100
$$

em que $A E C$ é agregados estáveis na classe, $M a$ a massa dos agregados aparentes na classe; $M p$, a massa das partículas primárias na classe; $M s$, a massa da amostra original antes da tamisagem; e $M w$, a massa de água na amostra original.

O diâmetro médio ponderado, introduzido por van Bavel (1949) como índice de agregação, foi calculado considerando a proporção em massa Wi de determinado tamanho de fração multiplicada pelo diâmetro médio $X i$ dessa fração. A soma desses produtos para todos os tamanhos de frações é chamada de diâmetro médio ponderado (DMP).

$$
D M P=\sum_{i=1}^{N} X i . W i
$$

A resistência à penetração foi determinada com amostras de solo com estrutura indeformada (cilindros de 0,05 $\mathrm{m}$ de altura e 0,05 $\mathrm{m}$ de diâmetro), com teor de água correspondente a uma tensão de $10 \mathrm{kPa}$ (Silva et al., 1994) utilizando um penetrômetro eletrônico estático de laboratório com velocidade constante de penetração de $0,01 \mathrm{~m} \mathrm{~min}^{-1}$, registro de uma leitura por segundo, cone com ângulo de $60^{\circ} \mathrm{e}$ área de $12,566 \mathrm{~mm}^{2}$, equipado com atuador linear de célula de carga de $20 \mathrm{kgf}$, acoplado a um microcomputador para aquisição dos dados, conforme descrito por Tormena et al. (1998). Foram realizadas três subdeterminações por amostra com 180 leituras por subdeterminação. A resistência à penetração foi representada pelo valor médio das 540 leituras (três subdeterminações).

A infiltração da água foi medida na superfície do solo, com infiltrômetro de tensão (Perroux \& White, 1988) nas tensões de 0 e $5 \mathrm{hPa}$. O ensaio de infiltração foi concluído quando, pelo menos, quatro leituras consecutivas apresentaram resultados similares, ou seja, quando o processo de infiltração da água no solo atingiu o equilíbrio estacionário. Com base no método de Ankeny et al. (1991), a partir da medida do fluxo para duas tensões, é possível determinar a condutividade hidráulica para cada tensão aplicada, segundo as equações a seguir:

$$
\begin{gathered}
K_{1}=\frac{q_{1}}{1+\frac{4}{\pi r \alpha}} ; K_{2}=\frac{q_{2}}{1+\frac{4}{\pi r \alpha}} \\
\alpha=\frac{2\left(q_{1}-q_{2}\right)}{\Delta \tau\left(q_{1}+q_{2}\right)}
\end{gathered}
$$

em que $K_{1}$ e $K_{2}$ são as condutividades hidráulicas para as tensões 1 e 2 , respectivamente; $q_{1}$ e $q_{2}$, os fluxos para as tensões 1 e 2 , respectivamente; $r$ é o raio da base do infiltrômetro; $\mathrm{e} \Delta \tau$, a diferença absoluta entre as tensões.

$\mathrm{O}$ experimento foi analisado em delineamento inteiramente casualizado em esquema de parcelas subdivididas $3 \times 3 \times 5$ (dois sistemas de manejo do solo - plantio do mamoeiro em sulco e camalhão - e mata nativa secundária; três camadas de solo - 0,00,1; 0,1-0,2 e 0,2-0,3 m; cinco repetições), com exceção para a condutividade hidráulica em que se adotou o esquema fatorial $3 \times 2 \times 5$ (dois sistemas de manejo do solo e mata nativa secundária; duas tensões - 0 e $5 \mathrm{hPa}$; cinco repetições). Todos os dados foram inicialmente analisados pela estatística descritiva clássica. Este procedimento foi aplicado para verificar a existência de valores periféricos (outliers) que comprometessem o comportamento médio dos parâmetros avaliados. Foram aplicados os testes de Kolmogorov-Smirnov para averiguar a normalidade dos dados, o $\mathrm{F}$ para a análise de variância e o de Tukey para a comparação de médias, todos a $5 \%$.

Também foram empregadas técnicas multivariadas de análise de componentes principais (ACP) para o entendimento de como os atributos interagiram ao 
mesmo tempo. Foram considerados os atributos areia, argila, silte, grau de floculação, densidade do solo, diâmetro médio ponderado, porcentagem de agregados estáveis, matéria orgânica e resistência à penetração nas camadas de $0,0-0,1 ; 0,1-0,2 ; 0,2-0,3$ e $0,0-0,3 \mathrm{~m}$, cujos valores originais foram normalizados para média igual 0 e variância igual a 1 , a fim de compor as variáveis utilizadas na ACP. Com a ACP para esses atributos foram gerados nove componentes.

À matriz de correlação dos atributos com os nove componentes, considerou-se o nível de significância de $5 \%$ para, então, selecionar os atributos tidos como significativos que apresentam alta correlação com o componente principal em que se encontram. Os atributos selecionados apresentaram correlação de no mínimo 0,6 em módulo, em pelo menos um dos componentes principais e, por esse motivo, nenhum deles foi excluído. Foi feita uma nova ACP, gerando dessa feita dois componentes principais (CP1 e CP2), que explicaram 90,5\% da variância dos dados originais. Para a análise de agrupamento das variáveis, utilizou-se o método de Ward, com a medida euclidiana para a distância entre os casos nos grupos.

\section{RESULTADOS E DISCUSSÃO}

A composição granulométrica dos solos em estudo está apresentada no quadro 1 , em que se observa diferença na classe textural do solo sob sistema em sulco, quando comparado aos sistemas em camalhão e mata para todas as faixas de profundidades. Essa diferença pode ter sido provocada pelo preparo do solo diferenciado nesses sistemas. Como os sulcos têm uma profundidade de 0,00-0,25 m, e o preparo do solo com a grade aradora foi somente até $0,20 \mathrm{~m}$, então, nessa camada de solo amostrada não houve revolvimento. Ressalta-se que a amostragem no sistema em sulco foi realizada no centro desse. Ao contrário, para o sistema de manejo em camalhão, para o levantamento desses, utilizou-se o solo revolvido pelo preparo com a grade aradora.

Nos três sistemas, o teor de argila aumentou enquanto o de areia diminuiu em profundidade. Comportamento semelhante foi observado por Mota et al. (2008), estudando propriedades físicas de um Cambissolo na Chapada do Apodi. Todas as classes texturais do solo sob os sistemas de manejo se enquadraram como solos de textura média.

Quanto ao grau de floculação das argilas, o solo da mata apresentou maiores valores em relação aos demais sistemas. Possivelmente, esse maior grau de dispersão das argilas nos sistemas sob camalhão e sulco tenha sido em razão do efeito do íon $\mathrm{Na}$, proveniente da água de irrigação, presente em maior quantidade no solo dessas áreas, como também do preparo do solo com grade aradora, tendo em vista que o revolvimento do solo por esse implemento tem influência na dispersão da argila (Santos et al., 2012). Segundo Sposito (1989), o íon Na aumenta a espessura da dupla camada difusa na superfície das argilas, reduzindo as forças de atração entre elas, com consequente aumento na dispersão das partículas.

Freire et al. (2003) sugeriram um controle criterioso da água usada na irrigação, principalmente quando essa tem elevada relação de adsorção de $\mathrm{Na}$, o que favorece a dispersão dos coloides. Quando comparado o grau de floculação nas profundidades em estudo, praticamente não houve diferença entre essas.

A análise estatística para Ds apresentou ser o sistema em sulco menos denso em relação aos demais sistemas em todas as camadas (Figura 1). O sistema sob camalhão foi estatisticamente igual à mata nas camadas de $0,1-0,2 ; 0,2-0,3$ e 0,0-0,3 m. Quando comparando os sistemas dentro da camada de 0,0 $0,1 \mathrm{~m}$, verificou-se maior densidade para a mata. $\mathrm{O}$ fato de a mata ter apresentado maiores valores de Ds pode ser por causa de esse local ter sido no passado explorado com algum tipo de cultivo, o que pode ter acarretado em degradação física com consequente aumento de densidade. Outro ponto que merece destaque foi o fato de a mata ter passado considerável período de tempo após cultivos anteriores sofrendo processo de acomodação das partículas. Dessa forma, as partículas menores do solo (argila e silte) estão aumentando em profundidade, enquanto as maiores (areia) concentram-se em maior quantidade na camada superficial, contribuindo para o aumento da Ds nesse sistema. Já o solo sob cultivo de mamoeiro está sendo continuamente revolvido, por conseguinte favorecendo a uma menor Ds.

Mota et al. (2008), estudando propriedades físicas de solos da Chapada do Apodi cultivados com melão, encontraram para um Cambissolo, da superfície até $0,3 \mathrm{~m}$ de profundidade, valores de Ds de $1,46 \mathrm{~g} \mathrm{~cm}^{-3}$. Comparando esse valor com os obtidos neste estudo, observou-se que o sistema sob mata de 0,0- 0,2 $\mathrm{m}$ e sob camalhão de 0,1-0,2 m foram superiores.

Michelon (2005) estabeleceu valores críticos de Ds em função do teor de argila. Com base em sua classificação, os sistemas sob camalhão e mata na camada de 0,0-0,1 m se enquadraram na faixa de teor de argila de 0 a $20 \%$ com densidade crítica de $1,6 \mathrm{~g} \mathrm{~cm}^{-3}$, enquanto os demais tratamentos estão ajustados na faixa de 20 a $30 \%$ de argila com densidade crítica de $1,55 \mathrm{~g} \mathrm{~cm}^{-3}$. Confrontando os valores obtidos no trabalho com os considerados críticos para respectiva classe, observou-se inferioridade na Ds das áreas em estudo, ou seja, embora os valores de Ds estivessem elevados ainda não atingiram o limite crítico estabelecido como referência.

Em termos de Ds, pode-se considerar que os sistemas de manejos do solo sob cultivo de mamoeiro proporcionaram melhor condição física, na camada superficial, quando comparado à situação de referência, solo sob vegetação nativa secundária. 
Quadro 1. Características físicas do solo

\begin{tabular}{|c|c|c|c|c|c|c|c|c|c|c|c|c|}
\hline \multirow{2}{*}{$\begin{array}{l}\text { Sistema de } \\
\text { manejo }\end{array}$} & \multirow{2}{*}{ Prof. } & \multicolumn{6}{|c|}{$\operatorname{Areia}^{(1)}$} & \multirow{2}{*}{ Silte } & \multirow{2}{*}{ Argila } & \multirow{2}{*}{$\mathrm{AN}^{(2)}$} & \multirow{2}{*}{$\mathbf{G F}^{(3)}$} & \multirow{2}{*}{ Classe textural } \\
\hline & & MG & $\mathbf{G}$ & $\mathbf{M}$ & $\mathbf{F}$ & MF & Total & & & & & \\
\hline & $\mathrm{m}$ & & & & & $-\mathrm{g}$ & $\mathrm{xg}^{-1}$ & & & & $\%$ & \\
\hline \multirow[t]{4}{*}{ Camalhão } & $0,0-0,1$ & 134 & 81 & 94 & 173 & 66 & 548 & 270 & 182 & 111 & 39 & Franco-arenosa \\
\hline & $0,1-0,2$ & 137 & 79 & 90 & 166 & 59 & 529 & 258 & 213 & 126 & 41 & Franco-argiloarenosa \\
\hline & $0,2-0,3$ & 99 & 65 & 73 & 143 & 59 & 438 & 286 & 275 & 152 & 45 & Franco-argilosa \\
\hline & $0,0-0,3$ & 123 & 75 & 85 & 160 & 61 & 505 & 271 & 223 & 130 & 42 & Franco-argiloarenosa \\
\hline \multirow[t]{4}{*}{ Sulco } & $0,0-0,1$ & 115 & 76 & 75 & 144 & 61 & 471 & 296 & 232 & 163 & 30 & Franca \\
\hline & $0,1-0,2$ & 92 & 62 & 60 & 135 & 73 & 422 & 312 & 266 & 172 & 35 & Franca \\
\hline & $0,2-0,3$ & 87 & 55 & 53 & 141 & 74 & 409 & 322 & 269 & 177 & 34 & Franca \\
\hline & $0,0-0,3$ & 98 & 65 & 63 & 140 & 69 & 434 & 310 & 256 & 171 & 33 & Franca \\
\hline \multirow[t]{4}{*}{ Mata } & $0,0-0,1$ & 235 & 152 & 99 & 134 & 33 & 654 & 221 & 125 & 57 & 55 & Franco-arenosa \\
\hline & $0,1-0,2$ & 135 & 85 & 82 & 134 & 47 & 482 & 249 & 268 & 114 & 58 & Franco-argiloarenosa \\
\hline & $0,2-0,3$ & 121 & 81 & 65 & 113 & 45 & 425 & 276 & 299 & 130 & 57 & Franco-argilosa \\
\hline & $0,0-0,3$ & 164 & 106 & 82 & 127 & 42 & 520 & 249 & 231 & 100 & 57 & Franco-argiloarenosa \\
\hline
\end{tabular}

(1) MG: muito grossa (2,00-1,00 mm); G: grossa (1,00-0,50 mm); M: média (0,50-0,25 mm); F: fina (0,25-0,10 mm); e MF: muito fina $(<0,10-0,05 \mathrm{~mm}) ;{ }^{(2)} \mathrm{AN}$ : argila natural; ${ }^{(3)} \mathrm{GF}$ : grau de floculação.
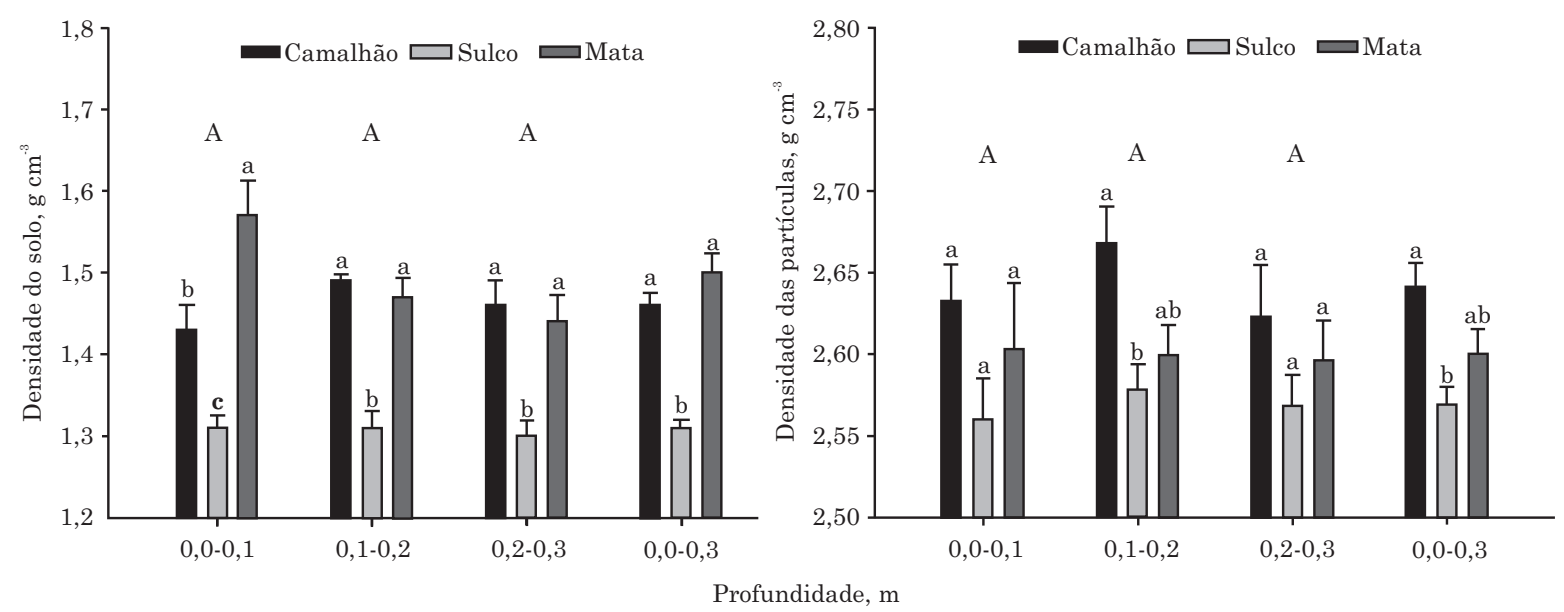

Figura 1. Densidade do solo e das partículas, com os desvios-padrão da média, para as áreas cultivadas com mamoeiro e mata nativa secundária. Médias seguidas pela mesma letra maiúscula entre profundidades, e pela mesma letra minúscula na mesma profundidade, não diferem pelo teste de Tukey a $5 \%$.

Em relação à densidade das partículas $(\mathrm{Dp})$ (Figura 1), não houve diferença estatística significativa entre os sistemas nas camadas de 0,0 0,1 e 0,2-0,3 m. Quando comparados na camada de $0,1-0,2$ e $0,0-0,3 \mathrm{~m}$, o camalhão apresentou com a mata maiores valores, sendo este último estatisticamente semelhante ao sulco. Essa maior $\mathrm{Dp}$ nos sistemas sob camalhão e mata nativa secundária foi ocasionada pelo maior teor de areia nessas áreas, visto que o principal componente dessa fração foi o quartzo, com densidade específica entre 2,65 a $2,66 \mathrm{~g} \mathrm{~cm}^{-3}$, elevando o valor da $\mathrm{Dp}$.

Quanto à agregação do solo, observou-se que o solo sob mata nativa secundária tem uma maior estabilidade de agregados, de tamanho entre $2 \mathrm{e}$
4,76 mm, quando comparado às áreas sob cultivo de mamoeiro (Figura 2). Esse comportamento pode ser mais bem explicado pelo teor de matéria orgânica, que nesse sistema é bem superior aos demais, sendo mais evidente na camada superficial, de 0,0-0,1 m (Figura 2). Também o que contribui é em razão de os sistemas de manejo realizarem o preparo convencional do solo de maneira inadequada, promovendo a pulverização desse, destruindo os agregados presentes, principalmente os de maiores tamanhos, colaborando para menor estabilidade dos agregados.

Resultado semelhante foi encontrado por Aratani et al. (2009), avaliando propriedades relacionadas à qualidade física de um Latossolo Vermelho, submetido a sistemas de uso e manejo. Os autores observaram 

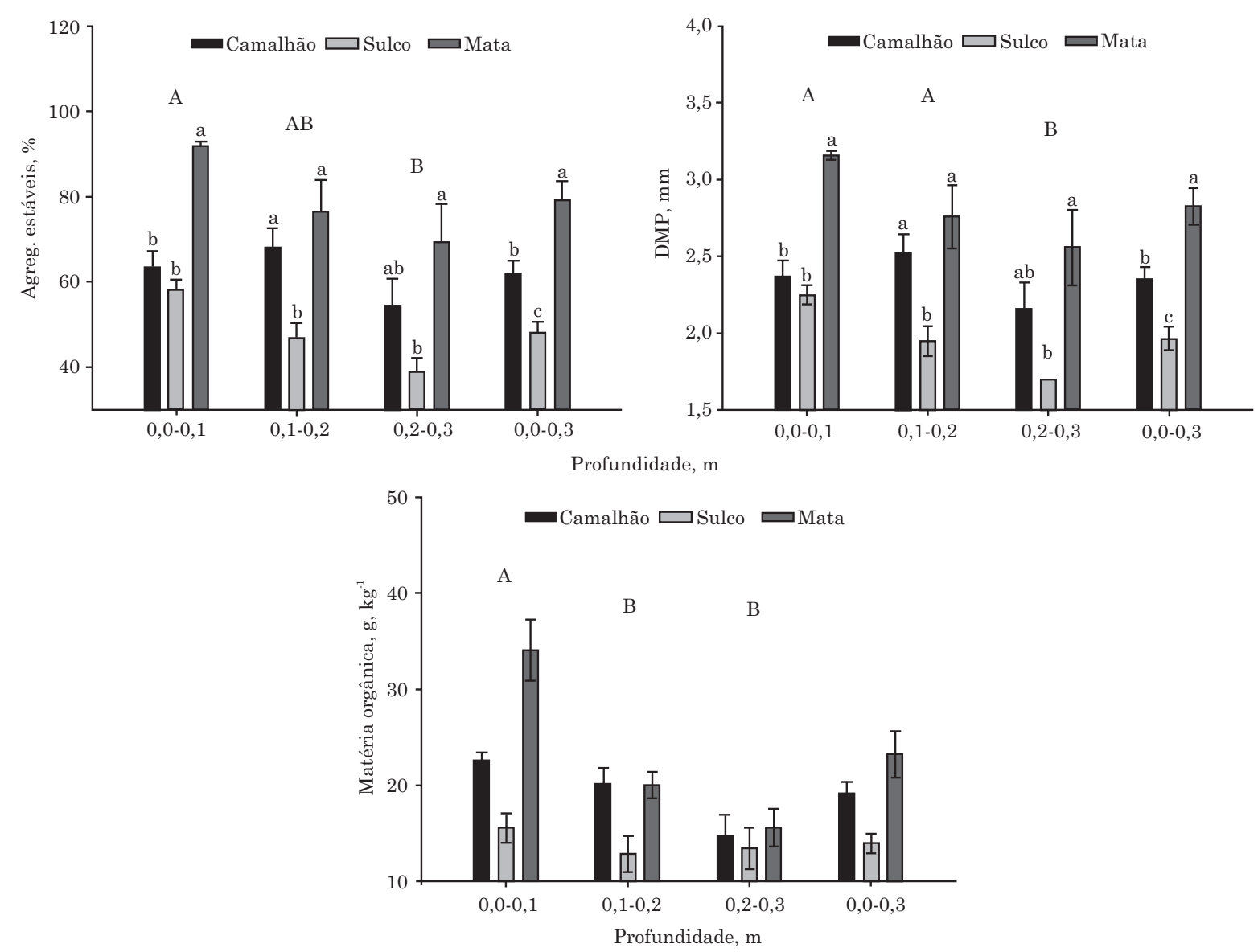

Figura 2. Estabilidade dos agregados $(4,76-2,00 \mathrm{~mm})$ em água, diâmetro médio ponderado e teores de matéria orgânica, com os desvios-padrão da média, para as áreas cultivadas com mamoeiro e mata nativa secundária. Médias seguidas pela mesma letra maiúscula entre profundidades, e pela mesma letra minúscula na mesma profundidade, não diferem pelo teste de Tukey a $5 \%$.

que o manejo do solo proporcionou redução dos índices de agregação, comprovada pela perda de estabilidade dos agregados por causa do uso agrícola, em relação à mata nativa. Esses justificaram que a maior agregação no sistema mata nativa foi resultante do acúmulo de matéria orgânica, influenciando fortemente a agregação do solo. Os sistemas sob cultivo, por revolverem o solo, destroem os agregados e favorecem a oxidação da matéria orgânica, causando redução do teor desse agente cimentante.

Além da ausência de revolvimento e do maior teor de matéria orgânica do solo sob mata, o maior grau de floculação das argilas na mata comparado aos outros sistemas favoreceu à maior agregação das partículas do solo, que, segundo Ferreira (2010), é uma condição necessária para estabilização do agregado. Dessa forma, a mata nativa secundária evidenciou-se mais resistente aos processos de erosão hídrica, quando comparada aos demais sistemas. Portanto, o solo das áreas sob cultivo de mamoeiro deve ser manejado de modo que promova o acúmulo e a preservação de matéria orgânica no perfil e, consequentemente, resultando em maior estabilização dos agregados.
Outro índice de agregação do solo, o DMP, revelou ser a mata isoladamente o melhor sistema na camada superficial (Figura 2). Quando se analisam as camadas de 0,1-0,2 e 0,2-0,3 $\mathrm{m}$ de profundidade, o sistema cultivado em camalhão se iguala ao sistema sob mata e ambos superam o sistema sob cultivo em sulco, com exceção da última camada em que o sulco não difere do sistema em camalhão. Comparando-se as profundidades, observou-se que as camadas superficiais $(0,0-0,1$ e $0,1-0,2 \mathrm{~m})$ foram superiores à camada mais profunda $(0,2-0,3 \mathrm{~m})$, sendo esse comportamento semelhante ao do índice de estabilidade de agregados em água, em que houve redução da estabilidade com o aumento da profundidade, o que pode ser atribuído ao teor de matéria orgânica que diminui em profundidade.

Leite (2011) encontrou valores de DMP para mata nativa de 3,04 e 2,74 $\mathrm{mm}$ e para área sob cultivo de goiaba de 3,02 e $2,76 \mathrm{~mm}$, nas profundidades de 0,00 0,15 e $0,15-0,30 \mathrm{~m}$, respectivamente. Esses valores estão condizentes com os observados neste estudo para a mata nativa secundária, já os da área sob cultivo de mamoeiro ficaram um pouco abaixo dos apresentados 
pelo autor para o cultivo de goiabeira. De qualquer forma, os valores de DMP para todos os sistemas de manejo permaneceram superiores a $0,5 \mathrm{~mm}$, valor considerado por Kiehl (1979) como limite entre baixa e alta estabilidade. Do mesmo modo que o teor de matéria orgânica contribuiu para maior estabilidade dos agregados, também concorreu para aumentar o tamanho dos agregados. Os índices indicaram o solo com cultivo de mamoeiro com menor agregação que a mata. Assim, tornou-se evidente que o revolvimento do solo por operações como o preparo do solo (aração, gradagem etc.), especialmente sob más condições de umidade, causou a destruição dos agregados do solo, reduzindo o tamanho e estabilidade deles.

Na camada de 0,1-0,2 m, não houve diferença significativa na resistência à penetração (Figura 3 ), enquanto nas camadas de 0,2-0,3 e 0,0-0,3 m o sulco e a mata, respectivamente, revelaram maior resistência à penetração em relação ao camalhão. Uma explicação razoável é em razão de o camalhão ter sido formado pelo solo revolvido no preparo, enquanto o solo apresentado nos sistemas mata e sulco não foi revolvido. De acordo com Giarola et al. (2007), a presença de argila dispersa em água pode contribuir para o aumento da resistência à penetração. Esse deve ter sido um dos motivos pelos quais o sistema em sulco teve superioridade sobre os demais, haja vista que nessa camada os valores de argila dispersa em água foram elevados, além de baixo grau de floculação e diâmetro médio ponderado, o que contribuiu para pior estruturação e consequente aumento da resistência à penetração.

Quando foram comparadas as camadas, observouse aumento da resistência em profundidade, resultado da deposição de partículas finas das camadas superiores para as inferiores, visto que houve aumento de silte e argila dispersa em água em profundidade, como também do teor de matéria orgânica e do DMP que diminuíram com o aumento da profundidade, contribuindo para o aumento da resistência à penetração. Ralisch et al. (2007), estudando o comportamento da resistência à penetração em sistemas de manejo do solo, verificaram aumento da resistência em profundidade até os $30 \mathrm{~cm}$ para o preparo convencional. A resistência à penetração nos tratamentos em estudo não atingiu o limite crítico para o desenvolvimento de plantas, 2,0 MPa (Silva et al., 1994).

Analisando o gráfico do log da condutividade hidráulica do solo (Figura 4) em razão da tensão com que a água se encontra no solo, observou-se diferença estatística significativa para as duas tensões em estudo. $\mathrm{Na}$ tensão de $0 \mathrm{hPa}$ (condutividade hidráulica em solo saturado), os sistemas em sulco e camalhão apresentaram maior condutividade, sendo esse último semelhante à do solo sob mata. De acordo com a classificação Soil Survey Staff (1993), para a condutividade hidráulica em solo saturado, todos os sistemas se enquadraram

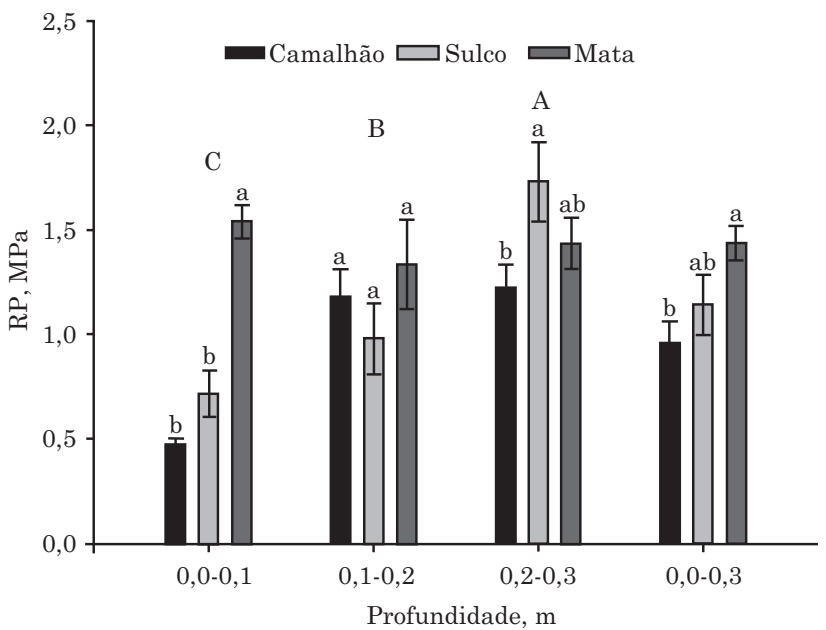

Figura 3. Resistência do solo à penetração, com os desvios-padrão da média, para as áreas cultivadas com mamoeiro e mata nativa secundária. Médias seguidas pela mesma letra maiúscula entre profundidades, e pela mesma letra minúscula na mesma profundidade, não diferem pelo teste de Tukey a $5 \%$.

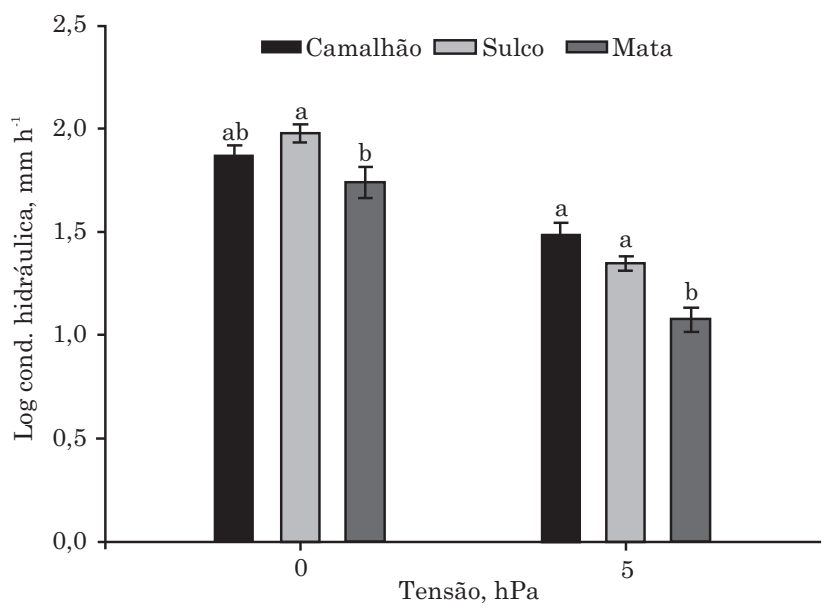

Figura 4. Condutividade hidráulica da superfície do solo, com desvios-padrão da média, para os sistemas de manejo em sulco e camalhão e sob mata nativa secundária. Médias seguidas pela mesma letra minúscula na mesma tensão não diferem pelo teste de Tukey a $5 \%$.

na classe alta $\left(36\right.$ a $360 \mathrm{~mm} \mathrm{~h}^{-1}$ ). Esse comportamento do solo quanto à condutividade hidráulica em condição de saturação é muito bom, pois, como se tratam de áreas irrigadas, é necessário que o solo conduza água no mínimo com a mesma intensidade com que ela chega à sua superfície, evitando, assim, problemas relacionados com a erosão.

Para a tensão de $5 \mathrm{hPa}$, os sistemas em camalhão e sulco mantiveram-se superiores à mata. É perceptível que com um pequeno acréscimo na tensão ou decréscimo na umidade a condutividade hidráulica 
cai de maneira brusca, efeito da relação exponencial entre a condutividade hidráulica e a umidade do solo. Os valores de condutividade hidráulica foram muito superiores à lâmina de irrigação aplicada nas áreas sob cultivo, $2,25 \mathrm{~mm} \mathrm{~h}^{-1}$, o que indicou que não há risco de escoamento superficial e consequentemente erosão, pelo uso da irrigação.

A análise de componentes principais (ACP) foi realizada na matriz de dados constituída de nove variáveis. Conforme Vicini (2005), a escolha do número de fatores pode levar em conta diferentes critérios, sendo um desses a seleção de autovalores superiores a 1. Desse modo, foram selecionados apenas os componentes 1 e 2 por atenderem ao critério estabelecido. Esses dois componentes explicaram, juntos, 90,5\% da variância, sendo 72,24 e 18,26 \% da variância explicada pelos fatores $1 \mathrm{e} 2$, respectivamente (Quadro 2).

De acordo com o quadro 3, as variáveis que melhor explicaram ou mais contribuíram para o fator 1 foram areia, argila, silte, grau de floculação, densidade do solo, diâmetro médio ponderado, porcentagem de agregados estáveis e matéria orgânica; para o fator 2 , argila e resistência à penetração.

Analisando a figura 5, observa-se que praticamente todas as variáveis estão próximas ao círculo unitário, indicando boa contribuição aos componentes principais. O mesmo não ocorreu com os sistemas de manejo. O sistema sob mata nativa secundária, nas camadas subsuperficiais $(0,1-0,2$ e $0,2-0,3 \mathrm{~m}$ ) e na camada $0,0-0,3 \mathrm{~m}$, foi correlacionado mais fortemente com as variáveis grau de floculação, porcentagem de agregados estáveis, diâmetro médio ponderado, Ds e resistência à penetração, enquanto a camada superficial da mata nativa secundária teve maior influência dos atributos areia e matéria orgânica.

Os sistemas de cultivo em sulco, em todas as camadas, e camalhão, na camada de 0,2-0,3 m, por ter influência de variáveis relacionadas com a textura (argila e silte), e visto que esses são atributos que não variam com o tempo, foram menos susceptíveis ao manejo dado ao solo. O contrário ocorreu com o sistema mata nativa secundária e o em camalhão, da superfície até $0,2 \mathrm{~m}$ e $0,0-0,3 \mathrm{~m}$, sendo bastante influenciados por atributos que podem ser alterados pelo manejo dado ao solo.

Por meio do dendrograma, pode-se verificar a formação de três grupos (Figura 6). Um composto pelo sistema de cultivo em sulco ( $\mathrm{S} 1, \mathrm{~S} 2, \mathrm{~S} 3$ e $\mathrm{S} 4)$ e outro formado apenas pela camada superficial da mata nativa secundária (M1). O sistema de manejo em camalhão e a mata nativa secundária nas camadas subsuperficiais e também na de $0,0-0,3$ $\mathrm{m}$, compõem mais um grupo (M2, M3, M4, C1, C2, C3 e C4). Um ponto que mereceu destaque é a similaridade entre as camadas subsuperficiais e a de $0,0-0,3 \mathrm{~m}$ dos sistemas sob mata nativa secundária e camalhão. Da mesma forma, ocorreram nas mesmas camadas do sistema em sulco, o que pareceu estar relacionado à semelhança das classes texturais dessas camadas.

Quadro 3. Correlação dos atributos analisados com os componentes principais (CP) obtidos a partir dos atributos analisados

\begin{tabular}{lrr}
\hline Variável & CP1 & CP2 \\
\hline Areia & 0,90 & $-0,42$ \\
Argila & $-0,70$ & 0,65 \\
Silte & $-0,99$ & $-0,05$ \\
Grau de floculação & 0,76 & 0,59 \\
Densidade do solo & 0,92 & 0,18 \\
Diâmetro médio ponderado & 0,96 & 0,12 \\
Agregados estáveis & 0,97 & 0,11 \\
Matéria orgânica & 0,95 & $-0,22$ \\
Resistência à penetração & 0,18 & 0,76 \\
\hline
\end{tabular}

Quadro 2. Autovalores e percentual da variância explicada por cada componente

\begin{tabular}{|c|c|c|c|c|}
\hline \multirow{2}{*}{$\begin{array}{l}\text { Número } \\
\text { de componente }\end{array}$} & \multicolumn{4}{|c|}{$\begin{array}{c}\text { Autovalor } \\
\text { Extração do componente principal }\end{array}$} \\
\hline & Autovalor & $\begin{array}{l}\text { Variância } \\
\text { explicada }\end{array}$ & $\begin{array}{l}\text { Autovalor } \\
\text { acumulado }\end{array}$ & $\begin{array}{c}\text { Variância explicada } \\
\text { acumulada }\end{array}$ \\
\hline & & $\%$ & & $\%$ \\
\hline 1 & 6,50 & 72,24 & 6,50 & 72,24 \\
\hline 2 & 1,64 & 18,26 & 8,15 & 90,51 \\
\hline 3 & 0,63 & 7,02 & 8,78 & 97,52 \\
\hline 4 & 0,16 & 1,81 & 8,94 & 99,33 \\
\hline 5 & 0,05 & 0,56 & 8,99 & 99,89 \\
\hline 6 & 0,01 & 0,10 & 9,00 & 99,99 \\
\hline 7 & 0,00 & 0,01 & 9,00 & 100,00 \\
\hline 8 & 0,00 & 0,00 & 9,00 & 100,00 \\
\hline
\end{tabular}




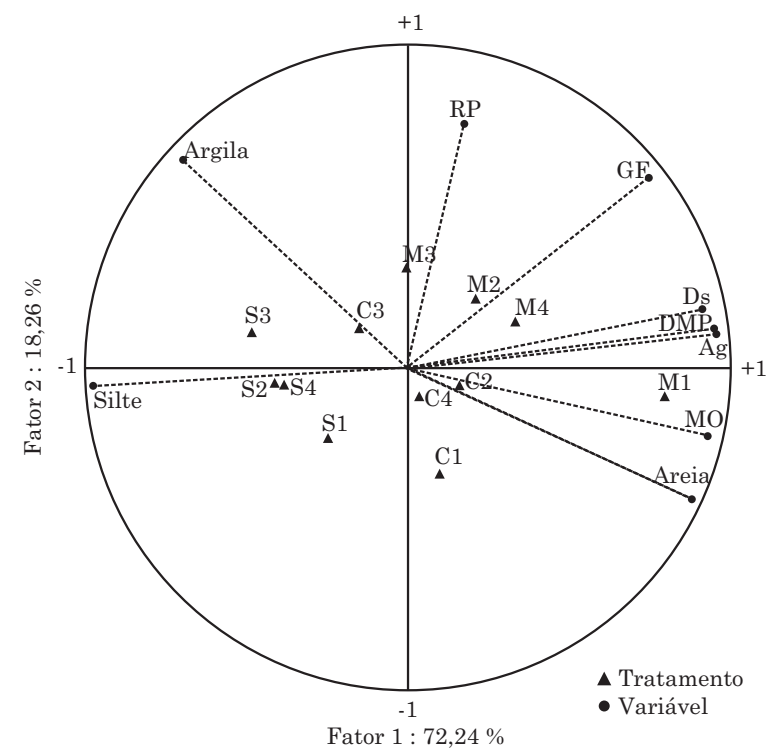

Figura 5. Dispersão dos atributos físicos em diferentes condições de uso do solo. Ag: porcentagem de agregados estáveis na classe ( $2,0 \mathrm{~mm})$; DMP: diâmetro médio ponderado; Ds: densidade do solo; GF: grau de floculação; MO: matéria orgânica; RP: resistência à penetração. C1, C2, C3 e C4 correspondem ao sistema de cultivo de mamoeiro sob camalhão; $\mathbf{S 1}, \mathbf{S} 2$, S3 e S4, ao sistema de cultivo de mamoeiro sob sulco; e M1, M2, M3 e M4, à mata nativa secundária, todos, respectivamente, às camadas de 0,0-0,1; 0,1-0,2; 0,2-0,3 e 0,0-0,3 m.

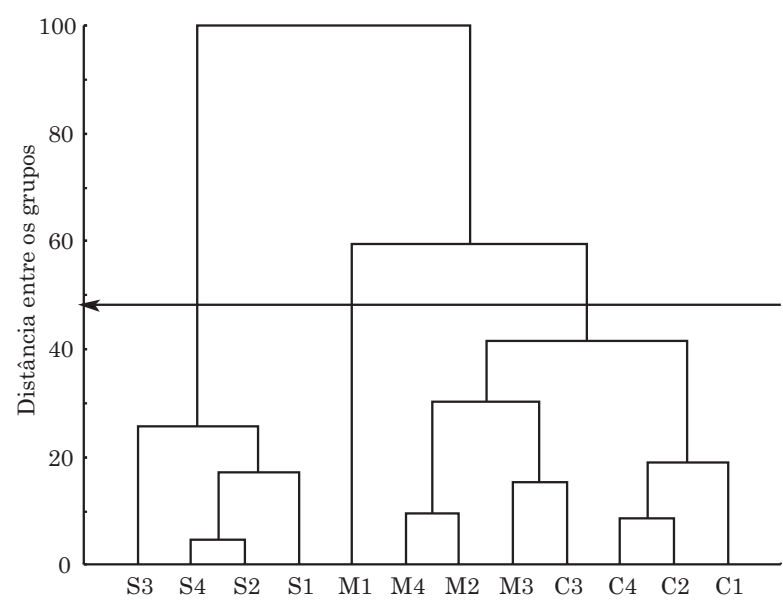

Figura 6. Dissimilaridade entre os grupos estabelecida por distância euclidiana a partir dos atributos argila, areia, silte, grau de floculação; porcentagem de agregados estáveis na classe (2,04,76 mm); diâmetro médio ponderado; matéria orgânica; densidade do solo; resistência à penetração. $\mathrm{C} 1, \mathrm{C} 2, \mathrm{C} 3$ e $\mathrm{C} 4$ correspondem ao sistema de cultivo de mamoeiro sob camalhão; $\mathrm{S1}$, S2, S3 e S4, ao sistema de cultivo de mamoeiro sob sulco; e M1, M2, M3 e M4, à mata nativa secundária, todos, respectivamente, às camadas de 0,0-0,1; 0,1-0,2; 0,2-0,3 e 0,0-0,3 m.

\section{CONCLUSÕES}

1. A hipótese de que os sistemas de cultivo degradam os solos fisicamente foi refutada, indicando que a qualidade dos atributos do solo sob cultivo, em geral, está mantida ou melhorada em relação à condição atual da mata nativa secundária.

2. O decréscimo do teor de matéria orgânica, da porcentagem de agregados estáveis na classe de 4,762,00 mm de diâmetro e do diâmetro médio ponderado em solo cultivado, apesar de ainda estarem distantes de limites considerados críticos, são sinalizadores da necessidade de adoção de práticas de manejo que evitem o desencadeamento de um processo de degradação do solo.

3. Os indicadores de qualidade foram sensíveis às alterações provocadas pelos sistemas de manejo do solo e, portanto, podem ser utilizados como fonte para a interpretação da dinâmica de processos físicos do solo no tempo.

\section{AGRADECIMENTOS}

Ao Conselho Nacional de Desenvolvimento Científico e Tecnológico (CNPq), pela concessão da bolsa de pesquisa ao segundo autor; e à Fundação Cearense de Apoio ao Desenvolvimento Científico e Tecnológico (FUNCAP), pelo apoio financeiro à pesquisa.

\section{LITERATURA CITADA}

ANKENY, M.D.; AHMED, M.; KASPAR, T.C. \& HORTON, R. Simple field method for determining unsaturated hydraulic conductivity. Soil Sci. Soc. Am. J., 55:467-470, 1991.

ARATANI, R.G.; FREDDI, O.S. \& CENTURION, J.F. Qualidade física de um Latossolo Vermelho acriférrico sob diferentes sistemas de uso e manejo. R. Bras. Ci. Solo, 33:677-687, 2009.

ASSIS, R.L. \& LANÇAS, K.P. Avaliação dos atributos físicos de um Nitossolo Vermelho distroférrico sob sistema plantio direto, preparo convencional e mata nativa. R. Bras. Ci. Solo, 29:515-522, 2005.

BAYER, C. \& MIELNICZUK, J. Dinâmica e função da matéria orgânica. In: SANTOS, G.A.; SILVA, L.S.; CANELLAS, L.P. \& CAMARGO, F.A.O., eds. Fundamentos da matéria orgânica do solo: ecossistemas tropicais e subtropicais. 2.ed. Porto Alegre, Metrópole, 2008. p.7-18.

BLAKE, G.R. \& HARTGE, K.H. Bulk density. In: KLUTE, A., ed. Methods of soil analysis. 2.ed. Madison, American Society of Agronomy, Soil Science Society of America, 1986a. Part 1. p.363-375. (Agronomy Monography, 9) 
BLAKE, G.R. \& HARTGE, K.H. Particle density. In: KLUTE, A., ed. Methods of soil analysis. 2.ed. Madison, American Society of Agronomy, Soil Science Society of America, 1986b. Part 1, p.377-382. (Agronomy Monography, 9)

BRASIL. Ministério de Agricultura. Departamento Nacional de Pesquisas Agropecuária. Divisão de Pesquisa Pedológica. Levantamento exploratório-reconhecimento dos solos do Estado do Ceará. Recife, 1973. 2v. (Boletim Técnico, 28), (Brasil, SUDENE - DRN. Divisão de Agrologia - Série Pedologia, 16)

CARVAlHO, G.J.; CARVALHO. M.P.; FREDDI, O.S. \& MARTINS, M.V. Correlação da produtividade do feijão com a resistência à penetração do solo sob plantio direto. R. Bras. Eng. Agríc. Amb., 10:765-771, 2006.

CHRISTENSEN, B.T. \& JOHNSTON, A.E. Soil organic matter and soil quality: Lessons learned from long-term experiments at Askov and Rothamsted. In: GREGORICH, E.G. \& CARTER, M.R., eds. Soil quality for crop production and ecosystem health. Amsterdam, Elsevier, 1997. p.399430 .

FERREIRA, M.M. Caracterização física do solo. In: JONG VAN LIER, Q., ed. Física do solo. Viçosa, MG, Sociedade Brasileira de Ciência do Solo, 2010. p.1-27.

FREIRE, M.B.G.S.; RUIZ, H.A.; RIBEIRO, M.R.; FERREIRA, P.A.; ALVAREZ V., V.H. \& FREIRE, F.J. Estimativa do risco de sodificação de solos de Pernambuco pelo uso de águas salinas. R. Bras. Eng. Agríc. Amb., 7:227-232, 2003.

GEE, G.W. \& BAUDER, J.W. Particle-size analysis. In: KLUTE, A., ed. Methods of soil analysis. 2.ed. Madison, American Society of Agronomy, Soil Science Society of America, 1986. Part 1. p.383-411. (Agronomy Monography, 9)

GIAROLA, N.F.B.; TORMENA, C.A. \& DUTRA, A.C. Degradação física de um Latossolo Vermelho utilizado para produção intensiva de forragem. R. Bras. Ci. Solo. 31:863-873, 2007.

IMHOFF, S.; SILVA, A.P. \& TORMENA, C.A. Aplicações da curva de resistência na qualidade física de um solo sob pastagem. Pesq. Agropec. Bras., 35:1493-1500, 2000.

KEMPER, W.D. \& ROSENAU, R.C. Aggregate stability and size distribution. In: KLUTE, A., ed. Methods of soil analysis. 2.ed. Madison, American Society of Agronomy, Soil Science Society of America, 1986. Part 1. p.425-442. (Agronomy Monography, 9)

KIEHL, E.J. Manual de edafologia: Relação solo-planta. Piracicaba, Ceres, 1979. 262p.

KLEIN, V.A. Física do solo. Passo Fundo, Universidade de Passo Fundo, 2008. 240p.

LEITE, H.M.F. Qualidade física do solo cultivado com goiabeira irrigada na Chapada do Apodi - CE. Fortaleza, Universidade Federal do Ceará, 2011. 98p. (Dissertação de Mestrado)

MICHELON, C.J. Qualidade física dos solos irrigados do Rio Grande do Sul e do Brasil Central. Santa Maria, Universidade Federal de Santa Maria, 2005. 115p. (Dissertação de Mestrado)
MOTA, J.C.A. Caracterização física, química e mineralógica, como suporte para o manejo, dos principais solos explorados com a cultura do melão na Chapada do Apodi. Fortaleza, Universidade Federal do Ceará, 2004. 96p. (Dissertação de Mestrado)

MOTA, J.C.A.; ASSIS JÚNIOR, R.N.; AMARO FILHO, J. \& LIBARDI, P.L. Algumas propriedades físicas e hídricas de três solos na Chapada do Apodi, RN, cultivados com melão. R. Bras. Ci. Solo, 32:49-58, 2008.

PERROUX, K.M. \& WHITE, I. Designs for disc permeameters. Soil Sci. Soc. Am. J., 52:1205-1215, 1988.

RALISCH, R.; MIRANDA, T.M.; OKUMURA, R.S.; BARBOSA, G.M.C.; GUIMARÃES, M.F.; SCOPEL, E. \& BALBINO, L.C. Resistência á penetração de um Latossolo VermelhoAmarelo do Cerrado sob diferentes sistemas de manejo. R. Bras. Eng. Agríc. Amb., 12:381-384, 2007.

REICHARDT, K. \& TIMM, L.C. Solo, planta e atmosfera: Conceitos, processos e aplicações. São Paulo, Manole, 2004. $478 \mathrm{p}$.

SALTON, J.C.; MIELNICZUK, J.; BAYER, C.; BOENI, M.; CONCEIÇÃO, P.C.; FABRÍCIO, A.C.; MACEDO, M.C.M. \& BROCH, D.L. Agregação e estabilidade de agregados do solo em sistemas agropecuários em Mato Grosso do Sul. R. Bras. Ci. Solo, 32:11-21, 2008.

SANTOS, D.S.; ARRUDA, E.M.; MORAES, E.R.; FRANCO, F.O.; ARAÚJO, J.R.; RESENDE, T.M.; BORGES, E.N. \& RIBEIRO, B.T. Atributos físicos e matéria orgânica de áreas de Latossolo utilizadas para atividade pecuária no bioma cerrado. Biosci. J., 28:500-508, 2012.

SILVA, A.P.; KAY, B.D. \& PERFECT, E. Characterization of the least limiting water range. Soil Sci. Soc. Am. J., 58:1775-1781, 1994.

SOIL SURVEY STAFF. Soil survey manual. Washington, USDA, 1993. 437p. (Handbook, 18)

SPOSITO, G. The chemistry of soils. New York, Oxford University Press, 1989. 277p.

TORMENA, C.A.; SILVA, A.P. \& LIBARDI, P.L. Caracterização do intervalo hídrico ótimo de um Latossolo Roxo sob plantio direto. R. Bras. Ci. Solo, 22:573-581, 1998.

van BAVEL, C.H.M. Mean weight diameter of soil aggregates as a statistical index of aggregation. Soil Sci. Soc. Am. Proc., 14:20-23, 1949.

VICINI, L. Análise multivariada da teoria à prática. Santa Maria, Universidade Federal de Santa Maria, 2005. 215p. (Monografia de Especialização)

WU, L.; PAN, L.; MITCHELL, J. \& SANDEN, B. Measuring saturated hydraulic conductivity using a generalized solution for single-ring inûltrometers. Soil Sci. Soc. Am. J., 63:788-792, 1999.

YEOMANS, J.C. \& BREMNER, J.M. A rapid and precise method for routine determination of organic carbon in soil. Commun. Soil Sci. Plant Anal., 19:1467-1476, 1988. 